\title{
The ruminal microbiome associated with methane emissions from ruminant livestock
}

\author{
IIma Tapio ${ }^{1}$, Timothy J. Snelling ${ }^{2}$, Francesco Strozzi ${ }^{3}$ and R. John Wallace ${ }^{2^{*}}$
}

\begin{abstract}
Methane emissions from ruminant livestock contribute significantly to the large environmental footprint of agriculture. The rumen is the principal source of methane, and certain features of the microbiome are associated with low/high methane phenotypes. Despite their primary role in methanogenesis, the abundance of archaea has only a weak correlation with methane emissions from individual animals. The composition of the archaeal community appears to have a stronger effect, with animals harbouring the Methanobrevibacter gottschalkii clade tending to be associated with greater methane emissions. Ciliate protozoa produce abundant $\mathrm{H}_{2}$, the main substrate for methanogenesis in the rumen, and their removal (defaunation) results in an average 11\% lower methane emissions in vivo, but the results are not consistent. Different protozoal genera seem to result in greater methane emissions, though community types ( $A, A B, B$ and $O$ ) did not differ. Within the bacteria, three different 'ruminotypes' have been identified, two of which predispose animals to have lower methane emissions. The two low-methane ruminotypes are generally characterized by less abundant $\mathrm{H}_{2}$-producing bacteria. A lower abundance of Proteobacteria and differences in certain Bacteroidetes and anaerobic fungi seem to be associated with high methane emissions. Rumen anaerobic fungi produce abundant $\mathrm{H}_{2}$ and formate, and their abundance generally corresponds to the level of methane emissions. Thus, microbiome analysis is consistent with known pathways for $\mathrm{H}_{2}$ production and methanogenesis, but not yet in a predictive manner. The production and utilisation of formate by the ruminal microbiota is poorly understood and may be a source of variability between animals.
\end{abstract}

Keywords: Archaea, Methane, Microbiome, Rumen

\section{Background}

Methane is a greenhouse gas (GHG) with a global warming potential 28-fold that of carbon dioxide [1]. Agriculture makes a significant contribution to total GHG production, with estimates varying according to country and calculation method [2]. Nonetheless, a global contribution of between 7 and $18 \%$ of total anthropogenic GHG emissions is generally accepted [2]. Ruminant production accounts for about $81 \%$ of GHG from the livestock sector (calculated from Hristov et al. [2]), $90 \%$ of which results from rumen microbial methanogenesis [3]. Ruminal $\mathrm{CH}_{4}$ production also represents a loss of energy (from 2 to $12 \%$ of gross energy intake [4]), which could in principle otherwise be available for animal growth or milk production. Lowering $\mathrm{CH}_{4}$

\footnotetext{
* Correspondence: john.wallace@abdn.ac.uk

${ }^{2}$ Rowett Institute of Nutrition and Health, University of Aberdeen, Foresterhill, Aberdeen AB16 5BD, UK

Full list of author information is available at the end of the article
}

emissions therefore would benefit the environment and possibly the efficiency of livestock production. More than $87 \%$ of the $\mathrm{CH}_{4}$ produced by sheep has been estimated to be derived from the rumen [5], where a population of methanogenic archaea converts the $\mathrm{H}_{2}$ and $\mathrm{CO}_{2}$ produced by a complex community of ciliate protozoa, bacteria and anaerobic fungi to $\mathrm{CH}_{4}[6,7]$. A massive worldwide research effort has investigated various mitigation strategies. Changes in management practices can be simple and very effective [2], while feed additives that might inhibit $\mathrm{H}_{2}$ production, provide an alternative metabolic $\mathrm{H}$ sink or inhibit the archaea themselves offer opportunities beyond those straightforward management changes [6-11]. Other opportunities include chemogenomics and immunization [12-14]. One strategy that is foremost in several investigations is genetic selection of the livestock. If we can demonstrate that persistently different $\mathrm{CH}_{4}$ emissions in different animals [14-16] can be explained by their individual 
ruminal microbiomes, and that the characteristic is heritable, it should be possible to select future generations of ruminants that have intrinsically lower $\mathrm{CH}_{4}$ emissions. All the strategies potentially involve changing the ruminal microbiome. The aim of this short review is to assess our current understanding of the role of different members of the microbiome in determining the extent of methanogenesis in the rumen.

\section{The rumen microbial community}

The rumen is home to a vast array of ciliate protozoa, anaerobic fungi, anaerobic bacteria and archaea. The protozoa can comprise up to half the rumen microbial biomass $[17,18]$, the fungi were originally estimated to be about $8 \%$ of the biomass [19] but may reach $20 \%$ in sheep [20], the archaea comprise $0.3-4 \%$ [21] and the bacteria form the remainder, typically the largest component of the microbial biomass. Our present understanding of ruminal microbiology was built initially upon a few epoch-changing advances made many years ago: Gruby \& Delafond's [22] microscopic observations of protozoa; Hungate's [23] appreciation of the anaerobic nature of the rumen that led to new, truly anaerobic culture techniques for the bacteria; Orpin's [24] realization that some flagellate protozoa were in fact zoospores of anaerobic fungi, until then a contradiction in terms. The isolation and study of pure cultures was and remains invaluable in understanding the likely role of different species of bacteria, protozoa or fungi in the overall fermentation. Drawbacks of cultivation techniques are that only a very small number of samples can be tested, and that they suffer from bias, whereby the composition of the growth medium, generally too rich, determines which species can grow [25]. Development of molecular techniques, based mainly on ssu rRNA gene and intergenic spacer sequence (for the fungi) analyses, opened new opportunities in rumen research. Cloning and sequencing provided community analyses that were not prone to the biases imposed by cultivation techniques, although different bias was introduced by other factors, like storage conditions [26], the differential efficiency of DNA extraction from different species and amplification bias [27-29]. Related techniques for microbiome analysis quickly followed (DGGE, TGGE, T-RFLP, ARISA). Quantitative PCR and FISH enabled microbial groups or species to be quantified [30]. Now, metagenomic sequencing enables rapid community analysis to be carried out, without the cultivation bias or variation associated with primer selection or PCR amplification irregularities $[25,31]$. The problem of DNA extraction remains, however, and databases are relatively weak where ruminal organisms are concerned [32]. Nevertheless, if we can use this approach to determine how the functional activity of the rumen microbial community influences methane emissions, the knowledge should enable strategies to decrease the environmental impact of livestock agriculture. Furthermore, it might be expected to improve animal production efficiency.

\section{Ruminal community analysis relating to methane emissions \\ Archaea}

There are two main routes for methanogenesis in the rumen, both carried out by archaea. The hydrogenotrophic pathway converts $\mathrm{H}_{2}$ and $\mathrm{CO}_{2}$ produced by the protozoa, bacteria and fungi to $\mathrm{CH}_{4}[3,6]$. It is usually assumed that formate, which can be used by all the most abundant ruminal archaea, is equivalent to $\mathrm{H}_{2}+\mathrm{CO}_{2}$, so formate is included in the hydrogenotrophic category $[21,33]$. A second category of substrate for methanogenesis is methyl groups, such as those present in methylamines and methanol $[34,35]$. Methylamines are derived from glycine betaine (from beet) and choline (from plant membranes), while methanol is derived from the hydrolysis of methanolic side-groups in plant polysaccharides. The most common hydrogenotrophic archaea are from the genus Methanobrevibacter, which has been divided into two subgroups, one known as the SGMT clade (Mbb. smithii, Mbb. gottschalkii, Mbb. millerae and $M b b$. thaueri), the other (RO) clade comprising principally $M b b$. ruminantium and $M b b$. olleyae [21, 36]. Other significant hydrogenotrophic genera include Methanosphaera, Methanimicrococcus and Methanobacterium. The less abundant methylotrophs (Methanosarcinales, Methanosphaera, Methanomassiliicoccaceae) can use methylamines and methanol, and there are archaea (Methanosarcinales) that produce methane via the aceticlastic pathway (reviewed in Morgavi et al. [7]). Rumen methanogenic archaeal diversity is restricted to four orders [21] and is highly conserved across 32 ruminant species collected worldwide [32].

Intuitively, archaea should be the microbial group most closely correlated with methane emissions. However, some studies have shown no such correlation with their overall abundance while in others the correlation has been weak. Morgavi et al. [37], Zhou et al. [38], Danielsson et al. [39] and Danielsson [40] found no correspondence between the numbers of methanogens and methane emissions from dairy cows when measured using metagenomics and qPCR techniques. Kittelmann et al. [41] and Shi et al. [42] formed a similar conclusion in sheep. A weak correlation between archaeal abundance relative to bacteria was found in beef steers [43] but none was found with dairy cows in the RuminOmics project [http://www.ruminomics.eu/] when expressed as the archaea:bacteria ratio (Fig. 1). Shi et al. [42] also observed that archaeal gene expression rather than gene abundance was correlated to methane emissions from 


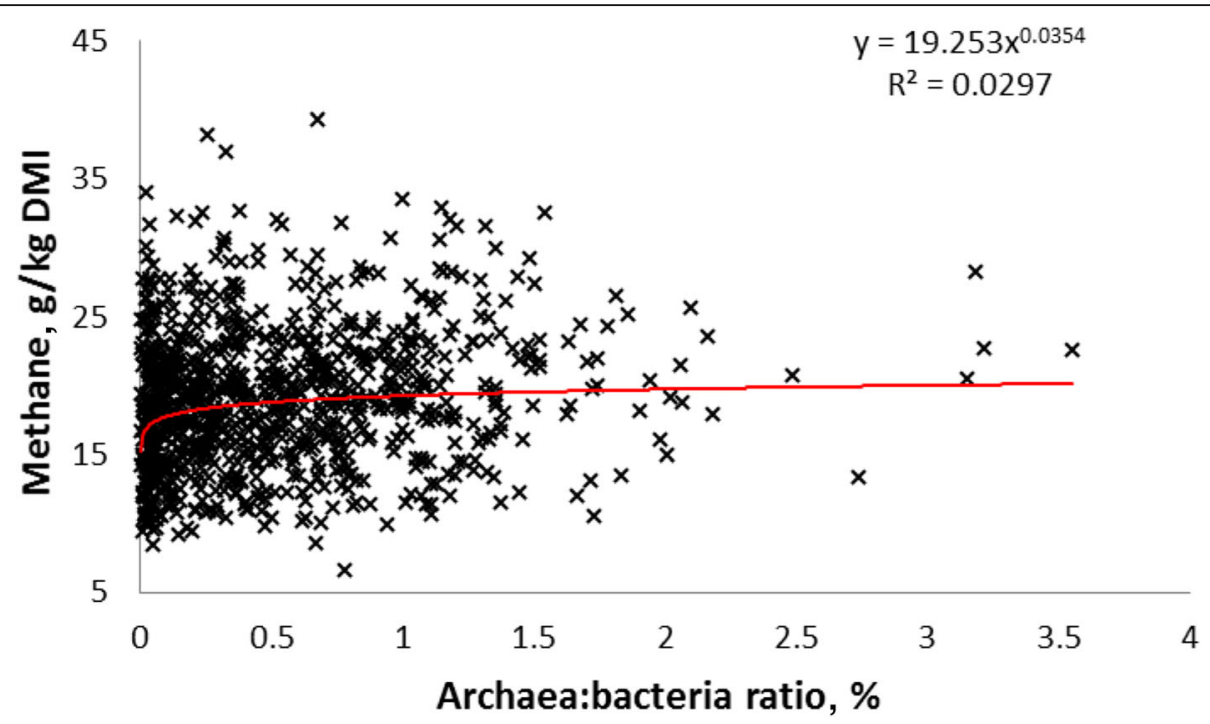

Fig. 1 Archaea:bacteria relative abundance in relation to methane emissions, preliminary data from the 1000-cow RuminOmics project. Dairy cows on different farms throughout Europe received grass or maize silage:concentrate diets of similar nutrient composition. Feed intake was measured either directly or calculated from faecal long-chain hydrocarbons. Samples of rumen contents were removed by stomach tube and DNA was extracted by the Yu \& Morrison method [110]. Abundances were calculated from qPCR of 16S rRNA genes using universal primers for archaea and bacteria

individual sheep. It is easy to see why gene expression might be a useful proxy for methanogenesis in a static system like soil [44], but less so in a flowing system like the rumen, where for physiological reasons biomass must be directly correlated to gene abundance unless other processes, such as uncoupled $\mathrm{CH}_{4}$ production occur [45].

Given the high variability of the relationship with overall archaeal abundance, it may be that the composition of the archaeal community rather than just its size may have greater significance with regard to methane emissions. Zhou et al. [38], Danielsson et al. [39], Shi et al. [42] and Danielsson [40] all found a positive correlation between the relative abundance of Methanobrevibacter SGMT clade and methane emissions. Danielsson [40] interpreted this correlation in terms of different affinities for $\mathrm{H}_{2}$ in the two groups, with the SGMT clade possessing methyl coenzyme $M$ reductase isozymes McrI and McrII [12], which enables the archaea to utilise $\mathrm{H}_{2}$ at higher concentrations, against the RO clade that possess only McrI $[3,12]$. The dynamics of the of the archaeal community composition and thus the efficiency of $\mathrm{H}_{2}$ utilization would in turn would be a consequence of differing $\mathrm{H}_{2}$ production by different bacteria $[33,41]$ and presumably also protozoal and fungal communities. Furthermore, the proportion of Methanosphaera spp. in total archaea was negatively associated with methane production in sheep [41], although not in beef cattle [46]. Thus, differing methane emissions are at least partly due to varying relative abundances within the community of methanogenic archaea.
Other observations regarding the archaeal community, sometimes called the archaeome, include those of Pitta et al. [47], who found that archaeal abundance increased in steers suffering frothy bloat, and Pei et al. [48], who discovered archaea associated with the rumen epithelium. In the former case, the $\mathrm{CH}_{4}$ content of the gas was not measured, so it is unclear the impact the bloat would have on methanogenesis. In the latter, the finding was surprising because the rumen wall is considered to be an aerobic/anaerobic interface, and the relative abundance of $\mathrm{O}_{2}$ might be considered to suppress the growth of the extremely $\mathrm{O}_{2}$-sensitive methanogens. In fact, one might have possibly expected $\mathrm{CH}_{4}$ oxidisers to be present, in spite of their absence from the deep ruminal digesta [49].

\section{Ciliate protozoa}

Ruminal ciliates are intimately involved in methanogenesis, partly via their abundant $\mathrm{H}_{2}$ production [50] and, taking advantage of this, their associated methanogens, which are found both as intracytoplasmic commensals and on the exterior surface of the protozoa $[3,18,51-53]$. Several studies suggested a correlation between the abundance of protozoa and methane emissions (collated in $[18,54,55])$, while others do not $[37,43]$. Guyader et al. [56] conducted a meta-analysis containing 28 experiments and 91 treatments. This meta-analysis showed a linear positive relationship between $\log _{10}$ protozoal numbers and methane emissions expressed per unit DMI. An $r=0.96$ showed that there is indeed a reasonably strong relationship (Fig. 2). 


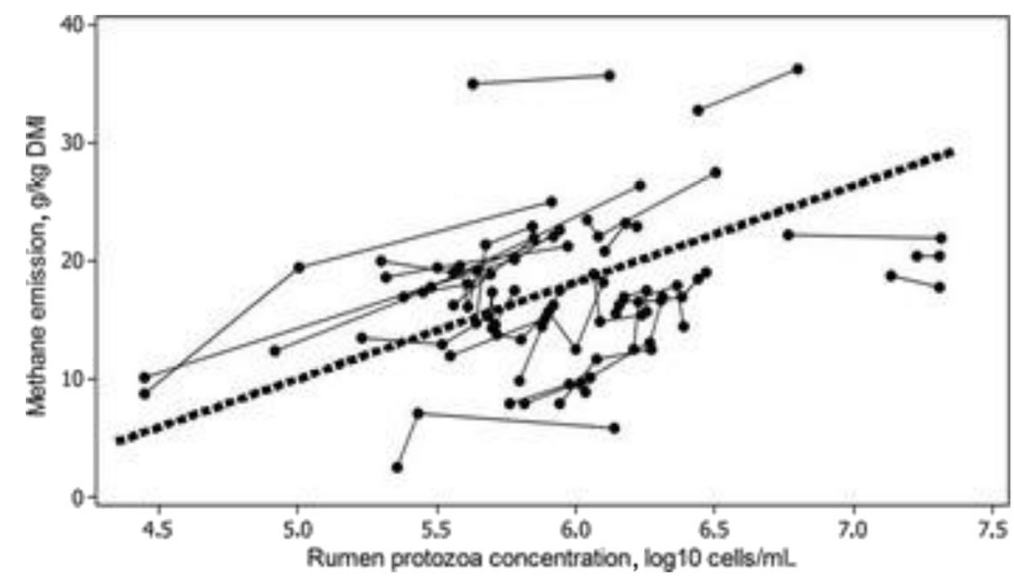

Fig. 2 Relationship between methane emission and rumen protozoa concentration in a meta-analysis of 28 different experiments. The black dashed line represents the average within-experiment relationship. Reproduced from [56] with permission

Defaunation (the removal of the ciliates from the rumen) has therefore been investigated in relation to methane production. Although in some cases the results of defaunation on $\mathrm{CH}_{4}$ emissions have not been encouraging [57-60], Newbold et al. [18] carried out a metaanalysis of defaunation studies and concluded that $\mathrm{CH}_{4}$ was decreased on average by $11 \%$. Despite the lower $\mathrm{CH}_{4}$ production, the total archaeal abundance was not significantly decreased in the Newbold et al. meta-analysis, suggesting that the archaeal community in defaunated animals may have a lower $\mathrm{CH}_{4}$-emitting specific activity than that of the protozoa-associated community.

As with the archaea, the questions then revert to whether some individual protozoal genera or species, and their associated archaea, are more linked with methanogenesis than others. In general, the protozoa harbour an archaeal population that, like the general archaeal community, is dominated by Methanobrevibacter spp. [61-64], although differences were observed in the abundance of different archaea found in the protozoa and in the non-associated archaea $[18,61,65]$ that might lead to different methanogenic specific activities in the two populations. Furthermore, archaeal colonisation abundance may differ between different protozoal species [51] and each may be associated with different predominant archaeal genera/species. Holotrichs in particular had an archaeal community that differed from entodiniomorphid protozoa [53]. Larger ciliates appear to be more heavily colonized by methanogens than smaller ciliates $[53,66]$, and also by bacteria, suggesting that there is not a selective colonisation by archaea [53]. The lower metabolic activity in terms of $\mathrm{H}_{2}$ production of the larger protozoal species per unit biomass [50, 54, 58 ] presumably explains that smaller protozoa, and their associated archaea, will be relatively more active in methanogenesis than larger species. Indeed, in vitro studies indicated that the smaller Entodinium spp. were more associated with methane production than larger species like Polyplastron multivesiculatum [50, 58]. In vivo studies are inconsistent, however. Refaunation experiments indicated that the abundance of Entodinium spp. [67, 68] or holotrichs [68] correlated with higher methane emissions. A large amplicon sequencing study in sheep nevertheless found no relationship between the relative abundance of different ciliates and methane emissions [41]. Furthermore, ciliate communities fall into a small number of types (A, AB, B and $O$ [69]) depending on interactions, principally inter-species predation. Despite the large differences in relative abundance of different protozoa types in the different community types, methane emissions could not be correlated with protozoal community structure [70]. The varying colonisation by archaea depending on the time after feeding [71] is another confounding factor in trying to evaluate the role of protozoa in methanogenesis.

\section{Bacteria}

Ruminal bacteria form the most diverse group within the rumen, capable of utilizing fibre, starch, protein and sugars [72]. Among numerous bacterial phyla found in different studies, Firmicutes, Bacteroidetes and Proteobacteria are the most abundant [32]. Fibrolytic bacteria, especially cellulolytic Ruminococcus and several Eubacterium spp (Firmicutes), are well studied $\mathrm{H}_{2}$ producers. On the other hand, the prominent cellulolytic genus, Fibrobacter, does not produce $\mathrm{H}_{2}$, while Bacteroidetes are net $\mathrm{H}_{2}$ utilizers [72]. Microbiome analysis has identified three different 'ruminotypes' that seemed to be associated with variations in methane production by sheep [41]. The low- $\mathrm{CH}_{4}$ production ruminotype Q was characterised by high relative abundances of the propionateproducing Quinella ovalis. Low- $\mathrm{CH}_{4}$ ruminotype $\mathrm{S}$ had 
higher abundances of lactate- and succinate-producing Fibrobacter spp., Kandleria vitulina, Olsenella spp., Prevotella bryantii, and Sharpea azabuensis. The high- $\mathrm{CH}_{4}$ production ruminotype $\mathrm{H}$ had higher relative abundances of species belonging to Ruminococcus, other Ruminococcaceae, Lachnospiraceae, Catabacteriaceae, Coprococcus, other Clostridiales, Prevotella, other Bacteroidales, and Alphaproteobacteria. The overall interpretation would be that methane emissions depend on the abundance of the $\mathrm{H}_{2}$-producing bacteria present; a corollary to this is the observation that chemical inhibition of methanogenesis in goats led to increases in the abundance of $\mathrm{H}_{2}$-consuming Prevotella and Selenomonas spp. [73]. Proteobacteria were 4-fold less abundant ( 2.7 vs. $11.2 \%$ of bacteria) in high emitting beef cattle [46] and a similar finding was made in dairy cows [40]. The dominant family among Proteobacteria was Succinivibrionaceae. This finding seems to parallel the high numbers of Succinivibrionaceae in the Tammar wallaby [74], which, like the ruminant, is a herbivorous foregut fermenter. It produces only about one-fifth of the methane per unit of feed intake of ruminants, which is attributed to the large community of Succinovibrionaceae. An intriguing additional observation common to these studies $[40,41]$ was that within different Prevotella OTUs, some were correlated with a high $\mathrm{CH}_{4}$ phenotype, while others were associated with low emissions. The different OTUs seem to cluster together (Fig. 3), suggesting functional versatility within the Prevotella genus. Further investigation of the phenotypes of these dominant ruminal bacteria is needed, which may well provide clues for future exploitation, particularly as some Prevotella are reported to produce formate [72].

In a dairy cattle study [75] with two $\mathrm{CH}_{4}$-mitigating feed additives, grapemarc and a combination of lipids and tannins, it was found that the microbiome differed from the control diet in a similar way. Faecalibacterium prausnitzii was over-represented in the low- $\mathrm{CH}_{4}$ diets, and other microbiome markers that could be predictive of low- $\mathrm{CH}_{4}$ phenotypes were identified. $F$. prausnitzii is a bacterial species that is abundant in the human colon [76] but is seldom mentioned in the context of the rumen. It may prove a useful marker, but it is not obvious how its properties could be mechanistically connected to the low- $\mathrm{CH}_{4}$ phenotype.

\section{Anaerobic fungi}

The anaerobic fungi, like the protozoa, produce abundant amounts of $\mathrm{H}_{2}$, along with $\mathrm{CO}_{2}$, formate and acetate as metabolic end products [77]. Six fungal genera have been detected in the rumen but recent molecular research suggests existence of several new taxa [78], with functions still to be understood. Methanogens are found in close association with fungal hyphae [79]. Although there is reason to suppose that fungal abundance might be related to methane emissions, reports are few. Kittelmann et al. [41] noted no difference in fungal community structure in relation to methane emissions from sheep. In the RuminOmics project, however, preliminary results suggest that two fungal species, Caecomyces communis and Neocallimastix frontalis, are negatively related to methanogenesis $(r=-0.50$ and $-0.45, P<0.001$; R.J. Wallace et al., unpublished]. The meta-analysis of Newbold et al. [18] noted that one of largest effects of defaunation, which leads to lower $\mathrm{CH}_{4}$ production, was a decrease in fungal abundance. Whether this decrease is a major or direct cause of lower $\mathrm{CH}_{4}$ production in defaunated animals is unclear.

\section{General considerations on variations in methanogenesis and the microbiome}

\section{Contribution of non-hydrogenotrophic methanogenesis}

The main substrates for methanogenesis in the rumen are known to be $\mathrm{H}_{2}+\mathrm{CO}_{2}$, formate and compounds containing methyl groups like the methylamines and methanol [21]. In the reviews already mentioned here, formate and $\mathrm{H}_{2}+\mathrm{CO}_{2}$ are usually considered to be equivalent as substrates for methanogenesis and formate is not treated separately. Formate feeds directly into the methanogenesis pathway at the very beginning via formate dehydrogenase [80]. Hungate et al. [81] estimated that $18 \%$ of methane was formed via formate rather than $\mathrm{H}_{2}+\mathrm{CO}_{2}$. Yet there are some important aspects of formate metabolism about which our understanding is incomplete. The relationship between bacterial abundances from microbiome estimates, above, was discussed in relation to whether bacteria form $\mathrm{H}_{2}$, as in other analyses [33, 41, 43, 46], with little indication about formate producers. There is a large uncertainty about bacterial formate production, reflected in the summary tables of Stewart et al. [72]. Although many species produce some formate, precise amounts are not known and therefore the importance of this production is difficult to estimate. Perhaps the Hungate 1000 collection (www.rmgnetwork.org/ hungate1000.html) could be used as a resource to make such measurements. At present, the Hungate 1000 project has its emphasis on strengthening genetic databases [3], but much phenotypic information is being collected alongside the main thrust of the project. Assessing bacterial formate production is further complicated by the knowledge that co-culture experiments demonstrate that the metabolism of some bacteria and fungi grown in the presence of methanogens can be pulled in the direction of $\mathrm{H}_{2}$ or formate production [82-85], so it is very difficult to be sure what the role of different species might be in the mixed rumen community. And perhaps most crucially, methanogenesis is not the sole fate of formate in the rumen. Hungate et al. [81] noted formate utilisation in the absence of 


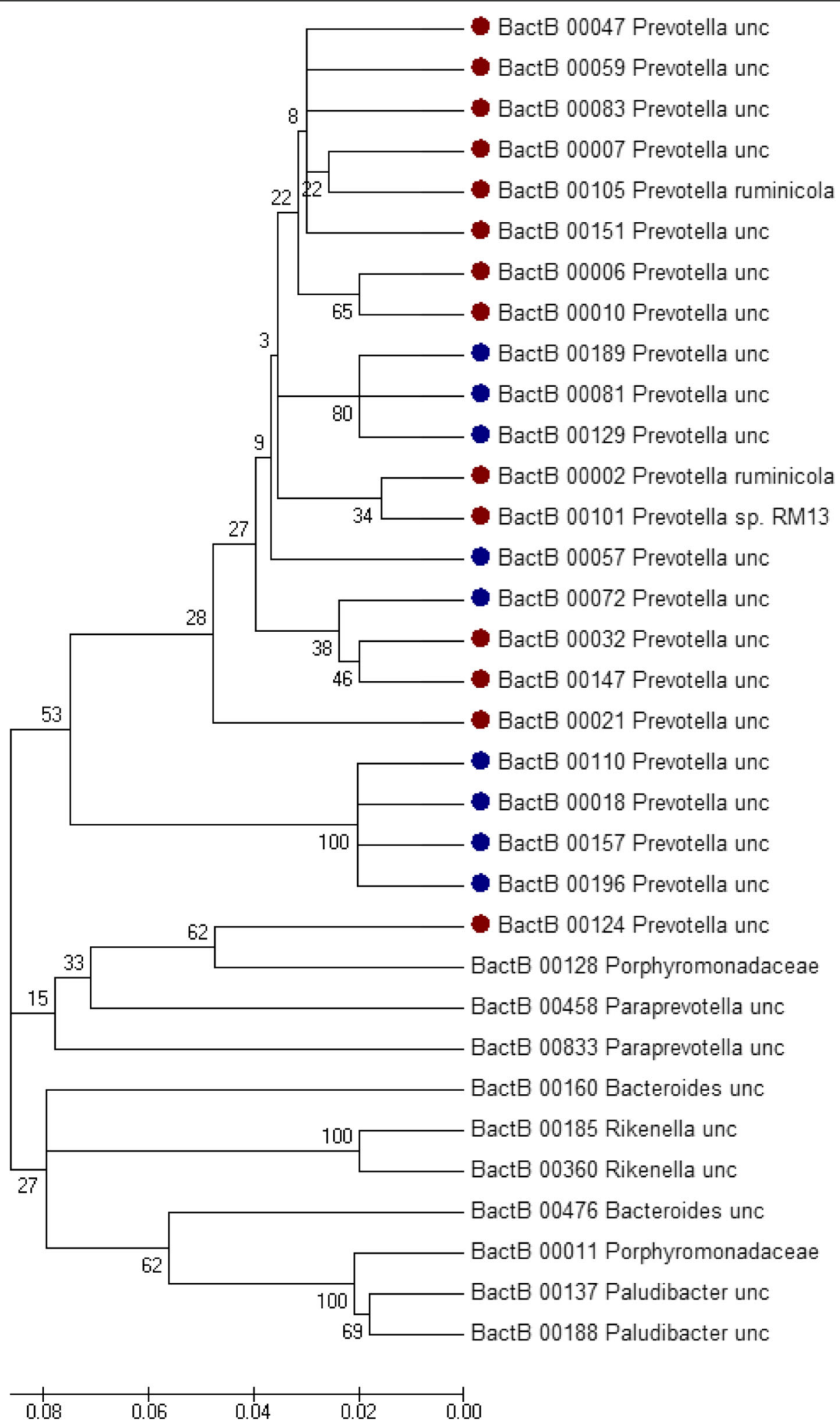

Fig. 3 Neighbor Joining tree of Prevotella-like OTUs that had a negative (blue dots) or positive (red dots) relation to methane (expressed in terms of $\mathrm{g}$ methane/kg DMI) in the 1,000-cow RuminOmics project. Multiple alignment was done using MUSCLE [1 11]. The Neighbor Joining tree was constructed using p-distance and pairwise-deletion parameters. The tree was resampled 1,000 times and bootstrap values are indicated. The linearized tree was computed using MEGA v5.1 [112] by using most abundant Bacteroidales OTUs to create an "outgroup" 
methanogenesis, presumably by bacteria. Species like Wolinella succinogenes use formate as an energy source [72]. So, although it is usually stated that ruminal archaea utilise either $\mathrm{H}_{2}+\mathrm{CO}_{2}$ or formate [3], it is unclear whether they are indeed equivalent for different archaea. For example, in co-cultures between rumen anaerobic fungi and three methanogens, all the methanogens used $\mathrm{H}_{2}$ but formate was only utilised simultaneously by M. smithii [86]. The differential expression of formate dehydrogenase was one of the largest differences between high- and low-emitting sheep [42]. The formate dehydrogenase of $M$. ruminantium M1 was induced by co-culture with the formate-producing Butyrivibrio proteoclasticus [12]. Thus there are several reasons to conclude that thinking about formate as a substrate in the context of microbiomes differing in their methanogenic activity might prove fruitful. Furthermore, despite the emphasis on $\mathrm{H}_{2}$ produced by ciliate protozoa, the quantity of formate produced seems to be many times greater than $\mathrm{H}_{2}$ [65].

The methylamines and methanol are methyl donors for methanogenesis by methylotrophic archaea, as described above. Their contribution to methanogenesis will depend to some extent on the concentration of methylamines in the diet $[34,35]$. But how efficient is the process? Are methylamines converted quantitatively to $\mathrm{CH}_{4}$, and are methylamine, dimethylamine and trimethylamine equivalent in that respect? It is possible that variation in $\mathrm{CH}_{4}$ emissions between individual animals on some diets may be due to different efficiencies whereby methylamines are released from feed materials and converted to $\mathrm{CH}_{4}$.

One of the more surprising findings in the $M b b$. ruminantium M1 genome was the presence of three genes encoding alcohol dehydrogenase [12]. It has been demonstrated that ethanol can be used as a $C$ source, but not as sole C source [3]. Thus, the availability of ethanol from bacterial fermentation may influence the dependence of archaea on methanogenesis for ATP production, and therefore affect the quantity of $\mathrm{CH}_{4}$ produced.

\section{Influence of diet and mitigation measures}

An important principle underlying this review is that some microbiomes lead to different $\mathrm{CH}_{4}$ emissions when other factors remain constant. Thus, key members of the microbiome leading to high or low emissions should be able to be identified. In the RuminOmics project, all dairy cows received diets that were as nutritionally similar as was possible given the different locations. Only by keeping as many other factors as possible unchanged will it be possible to dissect the role of different members of the microbial community in determining low- and highemitting individuals. It should be noted here that we have chosen to express $\mathrm{CH}_{4}$ production in terms of DMI, for the simple reason that it makes it easier to identify a low- $\mathrm{CH}_{4}$ microbiome rather than a microbiome that forms less $\mathrm{CH}_{4}$ only because the host animal eats less.

The results of microbiome analysis so far were expected in some respects, in the sense that diets high in starch content are known to lead to lower methane emissions, because starch utilising bacteria tend to produce less $\mathrm{H}_{2}$ than others, for example [33, 72]. In a similar way, the changed fermentation stoichiometry linked with methane emissions is a very long established observation [87, 88]. New questions have been highlighted regarding different species associated with high and low $\mathrm{CH}_{4}$ emissions under similar conditions. Unexpected correlations have been found. But many questions remain. It is also worth noting that widely different taxa may have similar metabolic activities [89], so there are several different microbiota that could lead to similar metabolic properties.

Mitigation measures have been described comprehensively elsewhere $[2,3,6-10]$. Perhaps the most promising of these is 3-nitrooxypropanol, a molecule obtained rationally by its structural similarity to methyl-CoM [90-92]. As yet we do not know the full implications of 3-nitrooxypropanol, but encouragement can be obtained that the concern that $\mathrm{H}_{2}$ accumulation might inhibit overall fermentation does not seem to be such a problem as was suggested by some in vitro experiments [33, 93]. It is also worth noting that a $50 \%$ reduction in the growth rate of methanogens would be sufficient to cause their washout from the rumen $[3,33]$. Complete inhibition of growth is therefore not necessary.

\section{Methane and feed efficiency}

$\mathrm{CH}_{4}$ production and feed efficiency are linked, in the sense that a low feed efficiency, expressed as residual feed intake (RFI), is accompanied by lower $\mathrm{CH}_{4}$ production [94-96]. The reverse does not apply, however, as has been found in dairy cows in the RuminOmics project. The findings that the abundance of certain Prevotella changes according to feed efficiency in beef cattle [97, 98] and many other taxa change in abundance [98] further emphasises our need to understand the role of Prevotella and its different biotypes on ruminal fermentation and methanogenesis. Shabat et al. [99] discovered that Megasphaera elsdenii was more abundant in low-efficiency cows, as were genes of the acrylate pathway, used by M. elsdenii in propionate formation. The explanation for lower efficiency was that $M$. elsdenii introduced a type of futile cycle in the production and subsequent utilisation of lactate, an energetically inefficient process.

\section{The influence of the host animal}

Many researchers believe, and some studies are beginning to show, that the host animal exerts a controlling 
effect on its own gut microbiota [100-102]. The mechanism could conceivably be at a molecular level, perhaps via complex interactions with receptors in the rumen wall $[103,104]$ or antibodies in saliva $[3,105,106]$. More likely, however, is that the physical structure and dynamics of gut digesta are different in different animals. Goopy et al [15] found that lower methanogenesis in sheep was heritable and accompanied by the animals' having smaller rumen volumes and therefore altered fluxes of nutrients through the tract. This would have the effect that less feed would be fermented in the rumen, leading to lower methanogenesis. Variations in saliva production could lead to a similar result [107]. Both would likely influence the ruminal microbiome. Therefore, caution should be exercised in interpreting microbiome analyses - the changed microbiome may be associated with, but not cause, a decrease in methanogenesis.

Ross et al. [108] found good correlations between $\mathrm{CH}_{4}$ emissions and the broad characteristics of the microbiome. Now, metagenomics has shown that the abundance of certain groups of microbial genes can be highly predictive of $\mathrm{CH}_{4}$ emissions $[46,109]$ and feed efficiency [99]. For example, 20 microbial genes explained $81 \%$ of variation in $\mathrm{CH}_{4}$ emissions from beef cattle, while 49 genes explained $86 \%$ of variation in RFI [109]. Furthermore, the animal's genetic background was a factor in determining these gene abundances [109]. This is the early phase of what is sure to be a fertile area in which animal-microbiome-emissions can be delineated by metagenomics profiling, and animal breeding based on these gene abundances may lead to animals with lower $\mathrm{CH}_{4}$ emissions.

\section{Conclusions}

Recent large scale projects such as the Global Rumen Census, the Hungate 1000 and RuminOmics, from which some preliminary results are presented here, have provided new depth of insight into the composition and function of the rumen microbial community. By revealing the some of the relationships between the microbiome and the animal phenotype, they have shown how understanding the role of the rumen microbiota can help in the efforts to reduce the environmental impact of livestock agriculture, in particular with the amelioration of greenhouse gas emissions. The archaea have been the main target for research, being directly associated with methane production in the rumen. However, other major microbial groups such as the ciliate protozoa, the anaerobic fungi, Succinovibrionaceae and Prevotella, among others, have shown to be associated with both high and low methane production. The results illustrate that there are basic phenotypic characteristics, such as formate metabolism, that are insufficiently understood. When placed in the context of the many as yet uncultivated microbial species of the rumen, it becomes clear that the powerful tool of molecular analysis must be accompanied by cultural and metabolic/phenotypic analysis if we are to truly understand the relation between the ruminal microbiome and methanogenesis.

\begin{abstract}
Abbreviations
ARISA: Automated ribosomal intergenic spacer analysis; DGGE: Density gradient gel electrophoresis; FISH: Fluorescence in vitro hybridization; qPCR: Quantitative polymerase chain reaction; TGGE: Temperature gradient gel electrophoresis; T-RFLP: Restriction fragment length polymorphism
\end{abstract}

\section{Acknowledgements}

The authors gratefully acknowledge the work of, and discussions with, other members of the RuminOmics consortium and thank them for their permission to use preliminary data to illustrate this article.

\section{Funding}

The Rowett Institute is funded by the Rural and Environment Science and Analytical Services Division (RESAS) of the Scottish Government. This study was financially supported by Ruminomics (project no. 289319 of EC 7th Framework Programme: Food, Agriculture, Fisheries and Biotechnology).

\section{Availability of data and materials}

The authors are bound by the Collaboration Agreement reached by the RuminOmics consortium, in which all data generated in the project become freely available in January 2018, but cannot be released without consent of the consortium before then. The original data underpinning Fig. 1 and Fig. 3 are subject to these conditions. Individual applications to release the data before 2018 should be directed to the corresponding author.

\section{Authors' contributions}

The authors wrote the manuscript together, RJW having initiated the project. All authors read and approved the final manuscript.

\section{Competing interests}

The authors declare that they have no competing interests.

\section{Consent for publication}

All authors have given their consent for submission of this article. The submission has also been approved by the publications committee of the RuminOmics consortium.

\section{Ethics approval}

Animal experimentation was conducted using protocols complying with national legislation and approved by local ethics committees.

\section{Author details}

${ }^{1}$ Green Technology, Natural Resources Institute Finland, Jokioinen, Finland. ${ }^{2}$ Rowett Institute of Nutrition and Health, University of Aberdeen, Foresterhill, Aberdeen AB16 5BD, UK. ${ }^{3}$ PTP, Via Einstein - Loc. Cascina Codazza, 26900 Lodi, Italy.

Received: 31 July 2016 Accepted: 3 January 2017

Published online: 19 January 2017

\section{References}

1. IPCC. Climate change 2014: synthesis report. In: Pachauri RK, Meyer LA, editors. Contribution of working groups I, II and III to the fifth assessment report of the intergovernmental panel on climate change. Geneva: IPCC; 2014. p. 151.

2. Hristov AN, Oh J, Lee C, Meinen R, Montes F, Ott F, et al. Mitigation of greenhouse gas emissions in livestock production. In: Gerber PJ, Henderson $\mathrm{B}$, Makkar HPS, editors. A review of options for non- $\mathrm{CO}_{2}$ emissions. Rome: FAO; 2013. p. 226.

3. McAllister TA, Meale SJ, Valle E, Guan LL, Zhou M, Kelly WJ, et al. Use of genomics and transcriptomics to identify strategies to lower ruminal methanogenesis. J Anim Sci. 2015;93:1431-49.

4. Johnson KA, Johnson DE. Methane emissions from cattle. J Anim Sci. 1995;73:2483-92. 
5. Murray RM, Bryant AM, Leng RA. Rates of production of methane in the rumen and large intestine of sheep. Br J Nutr. 1976;36:1-14.

6. Martin C, Morgavi DP, Doreau M. Methane mitigation in ruminants: from microbe to the farm scale. Animal. 2010;4:351-65.

7. Morgavi DP, Forano E, Martin C, Newbold CJ. Microbial ecosystem and methanogenesis in ruminants. Animal. 2010:4:1024-36.

8. Knapp JR, Laur GL, Vadas PA, Weiss WP, Tricarico JM. Invited review: enteric methane in dairy cattle production: quantifying the opportunities and impact of reducing emissions. J Dairy Sci. 2014;97:3231-61.

9. Kumar S, Choudhury PK, Carro MD, Griffith GW, Dagar SS, Puniya M, et al. New aspects and strategies for methane mitigation from ruminants. Appl Microbiol Biotechnol. 2014;98:31-44.

10. Beauchemin KA, Kreuzer M, O'Mara F, McAllister TA. Nutritional management for enteric methane abatement: a review. Aust J Exp Agric. 2008;48:21-7.

11. Attwood GT, Altermann E, Kelly WJ, Leahy SC, Zhang L, Morrison M. Exploring rumen methanogen genomes to identify targets for methane mitigation strategies. Anim Feed Sci Technol. 2011;166-67:65-75.

12. Leahy SC, Kelly WJ, Altermann E, Ronimus RS, Yeoman CJ, Pacheco DM, et al. The genome sequence of the rumen methanogen Methanobrevibacter ruminantium reveals new possibilities for controlling ruminant methane emissions. Plos One. 2010:5(1):e8926.

13. Wright ADG, Kennedy P, O'Neill CJ, Toovey AF, Popovski S, Rea SM, et al. Reducing methane emissions in sheep by immunization against rumen methanogens. Vaccine. 2004;22:3976-85.

14. Pinares-Patino CS, Hickey SM, Young EA, Dodds KG, MacLean S, Molano G, et al. Heritability estimates of methane emissions from sheep. Animal. 2013;7:316-21.

15. Goopy JP, Robinson DL, Woodgate RT, Donaldson AJ, Oddy VH, Vercoe PE, et al. Estimates of repeatability and heritability of methane production in sheep using portable accumulation chambers. Anim Prod Sci. 2015;56:116-22. http://dx.doi.org/10.1071/AN13370

16. de Haas Y, Windig JJ, Calus MPL, Dijkstra J, de Haan M, Bannink A, et al. Genetic parameters for predicted methane production and potential for reducing enteric emissions through genomic selection. J Dairy Sci. 2011;94:6122-34.

17. Hungate RE. The rumen and its microbes. New York: Academic; 1966

18. Newbold CJ, de la Fuente G, Belanche A, Ramos-Morales E, McEwan NR. The role of ciliate protozoa in the rumen. Front Microbiol. 2015;6:1313.

19. Orpin CG. Fungi in ruminant degradation. In: Agricultural science seminar: degradation of plant cell wall material. London: Agricultural Research Council; 1981. p. 129-50.

20. Rezaeian M, Beakes GW, Parker DS. Distribution and estimation of anaerobic zoosporic fungi along the digestive tracts of sheep. Mycol Res. 2004;108:1227-33.

21. Janssen PH, Kirs M. Structure of the archaeal community of the rumen. Appl Environ Microbiol. 2008;74:3619-25.

22. Gruby D, Delafond HMO. Recherches sur des animalcules se devélopant en grand nombre dans l'estomac et dans les intestins pemdant la digestion des animaux herbivores et carnivores. C R Hebd Seances Acad Sci. 1843;17:1304-8.

23. Hungate RE. Studies on cellulose fermentation. III the culture and isolation of cellulose-decomposing bacteria from the rumen of cattle. J Bacteriol. 1947;53:631-45.

24. Orpin CG. Studies on the rumen flagellate Neocallimastix frontalis. J Gen Microbiol. 1975;91:249-62.

25. Kenters N, Henderson G, Jeyanathan J, Kittelmann S, Janssen PH. Isolation of previously uncultured rumen bacteria by dilution to extinction using a new liquid culture medium. J Microbiol Meth. 2011:84:52-60.

26. McKain N, Genc B, Snelling TJ, Wallace RJ. Differential recovery of bacterial and archaeal 16S rRNA genes from ruminal digesta in response to glycerol as cryoprotectant. J Microbiol Meth. 2013;95:381-3.

27. Henderson G, Cox F, Kittelmann S, Miri VH, Zethof M, Noel SJ, et al. Effect of DNA extraction methods and sampling techniques on the apparent structure of cow and sheep rumen microbial communities. Plos One. 2013:8:e74787.

28. Kittelmann S, Seedorf H, Walters WA, Clemente JC, Knight R, Gordon Jl, et al. Simultaneous amplicon sequencing to explore co-occurrence patterns of bacterial, archaeal and eukaryotic microorganisms in rumen microbial communities. Plos One. 2013;8:e47879.

29. Tymensen LD, McAllister TA. Community structure analysis of methanogens associated with rumen protozoa reveals bias in universal archaeal primers. Appl Environ Microbiol. 2012;78:4051-6.
30. Zhou M, McAllister TA, Guan LL. Molecular identification of rumen methanogens: technologies, advances and prospects. Anim Feed Sci Technol. 2011;166-67:76-86.

31. Creevey CJ, Kelly WJ, Henderson G, Leahy SC. Determining the culturability of the rumen bacterial microbiome. Microb Biotechnol. 2014;7:467-79.

32. Henderson G, Cox F, Ganesh S, Jonker A, Young W, Janssen PH. Rumen microbial community composition varies with diet and host, but a core microbiome is found across a wide geographical range. Sci Rep. 2015;5:14567.

33. Janssen PH. Influence of hydrogen on rumen methane formation and fermentation balances through microbial growth kinetics and fermentation thermodynamics. Anim Feed Sci Technol. 2010;160:1-22.

34. Neill AR, Grime DW, Dawson RMC. Conversion of choline methyl groups through trimethylamine to methane in the rumen. Biochem J. 1978;170:529-35.

35. Poulsen M, Schwab C, Borg JB, Engberg RM, Spang A, Canibe N, et al. Methylotrophic methanogenic Thermoplasmata implicated in reduced methane emissions from bovine rumen. Nat Commun. 2013;4:1428.

36. Kittelmann S, Seedorf $\mathrm{H}$, Walters WA, Clemente JC, Knight R, Gordon Jl, et al. Simultaneous amplicon sequencing to explore co-occurrence patterns of bacterial, archaeal and eukaryotic microorganisms in rumen microbial communities. Plos One. 2013;8:e103171.

37. Morgavi DP, Martin C, Jouany JP, Ranilla MJ. Rumen protozoa and methanogenesis: not a simple cause-effect relationship. Br J Nutr. 2012;107:388-97.

38. Zhou M, Chung YH, Beauchemin KA, Holtshausen L, Oba M, McAllister TA, et al. Relationship between rumen methanogens and methane production in dairy cows fed diets supplemented with a feed enzyme additive. J Appl Microbiol. 2011;111:1148-58.

39. Danielsson R, Schnurer A, Arthurson V, Bertilsson J. Methanogenic population and $\mathrm{CH}_{4}$ production in Swedish dairy cows fed different levels of forage. Appl Environ Microbiol. 2012;78:6172-9.

40. Danielsson R. Methane production in dairy cows, Impact of feed and rumen microbiota; Acta universitatis agriculturae sueciae, 2016, doctoral thesis no. 2016. p. 45. Available at http://pub.epsilon.slu.se/13308/1/danielsson_r_160427.pdf.

41. Kittelmann S, Pinares-Patino CS, Seedorf H, Kirk MR, Ganesh S, McEwan JC, et al. Two different bacterial community types are linked with the low-methane emission trait in sheep. Plos One. 2014;9(7):e103171.

42. Shi WB, Moon CD, Leahy SC, Kang DW, Froula J, Kittelmann S, et al. Methane yield phenotypes linked to differential gene expression in the sheep rumen microbiome. Genome Res. 2014;24:1517-25.

43. Wallace RJ, Rooke JA, Duthie CA, Hyslop JJ, Ross DW, McKain N, et al. Archaeal abundance in post-mortem ruminal digesta may help predict methane emissions from beef cattle. Sci Rep. 2014;4:5892.

44. Freitag TE, Toet $\mathrm{S}$, Ineson P, Prosser Jl. Links between methane flux and transcriptional activities of methanogens and methane oxidizers in a blanket peat bog. FEMS Microbiol Ecol. 2010;73:157-65.

45. Costa KC, Yoon SH, Pan M, Burn JA, Baliga NS, Leigh JA. Effects of $\mathrm{H}_{2}$ and formate on growth yield and regulation of methanogenesis in Methanococcus maripaludis. J Bacteriol. 2013;195:1456-62.

46. Wallace RJ, Rooke JA, McKain N, Duthie CA, Hyslop JJ, Ross DW, et al. The rumen microbial metagenome associated with high methane production in cattle. BMC Genomics. 2015;16:839.

47. Pitta DW, Pinchak WE, Indugu N, Vecchiarelli B, Sinha R, Fulford JD. Metagenomic analysis of the rumen microbiome of steers with wheat-induced frothy bloat. Front Microbiol. 2016;7:689.

48. Pei CX, Mao SY, Cheng YF, Zhu WY. Diversity, abundance and novel 165 rRNA gene sequences of methanogens in rumen liquid, solid and epithelium fractions of Jinnan cattle. Animal. 2010;4:20-9.

49. Mitsumori M, Sun W. Control of rumen microbial fermentation for mitigating methane emissions from the rumen. Asian-Austral J Anim Sci. 2008;21:144-54.

50. Newbold CJ, Lassalas B, Jouany J-P. The importance of methanogens associated with ciliate protozoa in ruminal methane production in vitro. Lett Appl Microbiol. 1995;21:230-4.

51. Vogels GD, Hoppe WF, Stumm CK. Association of methanogenic bacteria with rumen ciliates. Appl Environ Microbiol. 1980;40:608-12.

52. Krumholz LR, Forsberg CW, Veira DM. Association of methanogenic bacteria with rumen protozoa. Can J Microbiol. 1983;29:676-80.

53. Belanche A, de la Fuente G, Newbold CJ. Study of methanogen communities associated with different rumen protozoal populations. FEMS Microbiol Ecol. 2014;90:663-77.

54. Coleman GS. The metabolism of rumen ciliate protozoa. FEMS Microbiol Rev. 1986;39:321-44. 
55. Williams AG, Coleman AG. The rumen protozoa. New York: Springer; 1992.

56. Guyader J, Eugene M, Noziere P, Morgavi DP, Doreau M, Martin C. Influence of rumen protozoa on methane emission in ruminants: a meta-analysis approach. Animal. 2014;8:1816-25.

57. Kreuzer M, Kirchgessner M, Müller $\mathrm{H}$. Effect of defaunation on the loss of energy in wethers fed different quantities of cellulose and normal or steamflaked maize starch. Anim Feed Sci Technol. 1986;16:233-41.

58. Ranilla MJ, Jouany JP, Morgavi DP. Methane production and substrate degradation by rumen microbial communities containing single protozoal species in vitro. Lett Appl Microbiol. 2007;45:675-80.

59. Bird SH, Hegarty RS, Woodgate R. Persistence of defaunation effects on digestion and methane production in ewes. Aust J Exp Agric Anim Prod Sci. 2008;48:152-5.

60. Hegarty RS, Bird SH, Vanselow BA, Woodgate R. Effects of the absence of protozoa from birth or from weaning on the growth and methane production of lambs. Br J Nutr. 2008;100:1220-7.

61. Sharp R, Ziemer CJ, Stern MD, Stahl DA. Taxon-specific associations between protozoal and methanogen populations in the rumen and a model rumen system. FEMS Microbiol Ecol. 1998;26:71-8.

62. Irbis C, Ushida K. Detection of methanogens and proteobacteria from a single cell of rumen ciliate protozoa. J Gen Appl Microbiol. 2004;50: 203-12.

63. Regensbogenova M, McEwan NR, Javorsky P, Kisidayova S, Michalowski T, Newbold CJ, et al. A re-appraisal of the diversity of the methanogens associated with the rumen ciliates. FEMS Microbiol Lett. 2004;238:307-13.

64. Tymensen LD, Beauchemin KA, McAllister TA. Structures of free-living and protozoa-associated methanogen communities in the bovine rumen differ according to comparative analysis of $16 \mathrm{~S}$ rRNA and mcrA genes. Microbiology. 2012;158:1808-17.

65. Tokura M, Ushida K, Miyazaki K, Kojima Y. Methanogens associated with rumen ciliates. FEMS Microbiol Ecol. 1997;22:137-43.

66. Lloyd D, Williams AG, Amann R, Hayes AJ, Durrant L, Ralphs JR. Intracellular prokaryotes in rumen ciliate protozoa: detection by confocal laser scanning microscopy after in situ hybridization with fluorescent 16S rRNA probes. Eur J Protistol. 1996;32:523-31.

67. Jouany J-P, Zainas B, Senaud J, Groliere CA, Grain J, Thivend P. Role of the rumen ciliate protozoa Polyplastron multivesiculatum, Entodinium sp. and Isotricha prostoma in the digestion of a mixed diet in sheep. Reprod Nutr Dev. 1981;21:871-84

68. Belanche A, de la Fuente G, Newbold CJ. Effect of progressive inoculation of fauna-free sheep with holotrich protozoa and total-fauna on rumen fermentation, microbial diversity and methane emissions. FEMS Microbiol Ecol. 2015;91:fiu026. doi:10.1093/femsec/fiu02613.

69. Eadie JM. Inter-relationships between certain rumen ciliate protozooa. J Gen Microbiol. 1962;29:579-88.

70. Kittelmann S, Pinares-Patino CS, Seedorf H, Kirk MR, McEwan JC, Janssen PH. Natural variation in methane emission of sheep fed on a lucerne pellet diet is unrelated to rumen ciliate community type. Microbiology. 2016;162:459-65.

71. Stumm CK, Gijzen HJ, Vogels GD. Association of methanogenic bacteria with ovine rumen ciliates. Br J Nutr. 1982:47:95-9.

72. Stewart CS, Flint HJ, Bryant MP. The rumen bacteria. In: Hobson PN, Stewart CS, editors. The rumen microbial ecosystem. London: Chapman \& Hall; 1997. p. 10-72.

73. Denman SE, Martinez FG, Shinkai T, Mitsumori M, McSweeney CS. Metagenomic analysis of the rumen microbial community following inhibition of methane formation by a halogenated methane analog. Front Microbiol. 2015;6:1087.

74. Pope PB, Smith W, Denman SE, Tringe SG, Barry K, Hugenholtz P, et al. Isolation of Succinivibrionaceae implicated in low methane emissions from tammar wallabies. Science. 2011;333:646-8.

75. Ross EM, Moate PJ, Marett L, Cocks BG, Hayes BJ. Investigating the effect of two methane-mitigating diets on the rumen microbiome using massively parallel sequencing. J Dairy Sci. 2013;96:6030-46.

76. Sokol H, Pigneur B, Watterlot L, Lakhdari O, Bermudez-Humaran LG, Gratadoux JJ, et al. Faecalibacterium prausnitzii is an anti-inflammatory commensal bacterium identified by gut microbiota analysis of Crohn disease patients. Proc Natl Acad Sci. 2008;105:16731-6.

77. Gruninger RJ, Puniya AK, Callaghan TM, Edwards JE, Youssef N, Dagar SS, et al. Anaerobic fungi (phylum Neocallimastigomycota): advances in understanding their taxonomy, life cycle, ecology, role and biotechnological potential. FEMS Microbiol Ecol. 2014;90:1-17.
78. Koetschan C, Kittelmann S, Lu J, Al-Halbouni D, Jarvis GN, Müller T, et al. Internal transcribed spacer 1 secondary structure analysis reveals a common core throughout the anaerobic fungi (Neocallimastigomycota). PLoS One. 2014;9:e91928.

79. Bauchop T. The anaerobic fungi in rumen fibre digestion. Agric Environ. 1981;6:339-48.

80. Thauer RK, Kaster AK, Seedorf H, Buckel W, Hedderich R. Methanogenic archaea: ecologically relevant differences in energy conservation. Nature Rev Microbiol. 2008:6:579-91.

81. Hungate RE, Smith W, Bauchop T, Yu I, Rabinowitz JC. Formate as an intermediate in the bovine rumen fermentation. J Bacteriol. 1970;102:389-97.

82. Bauchop T, Mountfort DO. Cellulose fermentation by a rumen anaerobic fungus in both the absence and presence of rumen methanogens. Appl Environ Microbiol. 1981;42:1103-10.

83. Wolin MJ, Miller TL, Stewart CS. Microbe-microbe interactions. In: Hobson PN, Stewart CS, editors. The rumen microbial ecosystem. London: Chapman \& Hall; 1997. p. 467-91.

84. Joblin KN, Williams AG. Effect of cocultivation of ruminal chytrid fungi with Methanobrevibacter smithii on lucerne stem degradation and extracellular fungal enzyme activities. Lett Appl Microbiol. 1991;12:121-4.

85. Joblin KN, Naylor GE, Williams AG. Effect of Methanobrevibacter smithii on xylanolytic activity of anaerobic ruminal fungi. Appl Environ Microbiol. 1990;56:2287-95.

86. Marvin-Sikkema FD, Richardson AJ, Stewart CS, Gottschal JC, Prins RA. Influence of hydrogen-consuming bacteria on cellulose degradation by anaerobic fungi. Appl Environ Microbiol. 1990;56:3793-7.

87. Demeyer DI, Van Nevel CJ. Methanogenesis, an integrated part of carbohydrate fermentation and its control. In: McDonald IW, Warner ACl, editors. Digestion and metabolism in the ruminant. Armidale: The University of New England Publishing Unit; 1975. p. 366-82.

88. Czerkawski JW. Methane production in the rumen and its significance. Wld Rev Nutr Diet. 1969;11:240-82.

89. Taxis TM, Wolff S, Gregg SJ, Minton NO, Zhang C, Dai J, et al. The players may change but the game remains: network analyses of ruminal microbiomes suggest taxonomic differences mask functional similarity. Nucleic Acids Res. 2015:43:9600-12.

90. Martinez-Fernandez G, Abecia L, Arco A, Cantalapiedra-Hijar G, Martin-Garcia Al, Molina-Alcaide E, et al. Effects of ethyl-3-nitrooxypropionate and 3-nitrooxypropanol on ruminal fermentation, microbial abundance, and methane emissions in sheep. J Dairy Sci. 2014;97:3790-9.

91. Reynolds CK, Humphries DJ, Kirton P, Kindermann M, Duval S, Steinberg W. Effects of 3-nitrooxypropanol on methane emission, digestion, and energy and nitrogen balance of lactating dairy cows. J Dairy Sci. 2014;97:3777-89.

92. Hristov AN, Oh J, Giallongo F, Frederick TW, Harper MT, Weeks HL, et al. An inhibitor persistently decreased enteric methane emission from dairy cows with no negative effect on milk production. Proc Natl Acad Sci. 2015;112:10663-8.

93. Morvan B, Rieu-Lesme F, Fonty G, Gouet P. In vitro interactions between rumen $\mathrm{H}_{2}$-producing cellulolytic microorganisms and $\mathrm{H}_{2}$-utilizing acetogenic and sulfate-reducing bacteria. Anaerobe. 1996;2:175-80.

94. Nkrumah JD, Okine EK, Mathison GW, Schmid K, Li C, Basarab JA, et al. Moore SS Relationships of feedlot feed efficiency, performance, and feeding behavior with metabolic rate, methane production, and energy partitioning in beef cattle. J Anim Sci. 2006;84:145-53.

95. Hegarty RS, Goopy JP, Herd RM, McCorkell B. Cattle selected for lower residual feed intake have reduced daily methane production. J Anim Sci. 2007:85:1479-86.

96. Muro-Reyes A, Gutierrez-Banuelos H, Diaz-Garcia LH, Gutierrez-Pina FJ, Escareno-Sanchez LM, Banuelos-Valenzuela R, et al. Potential environmental benefits of residual feed intake as strategy to mitigate methane emissions in sheep. J Anim Veter Adv. 2011;10:1551-6.

97. Carberry CA, Kenny DA, Han S, McCabe MS, Waters SM. Effect of phenotypic residual feed intake and dietary forage content on the rumen microbial community of beef cattle. Appl Environ Microbiol. 2012;78:4949-58.

98. Myer PR, Smith TPL, Wells JE, Kuehn LA, Freetly HC. Rumen microbiome from steers differing in feed efficiency. PLoS One. 2015;10:e0129174. doi:10.1371/journal.pone.0129174.

99. Shabat SK, Sasson G, Doron-Faigenboim A, Durman T, Yaacoby S, Berg Miller ME, et al. Specific microbiome-dependent mechanisms underlie the energy harvest efficiency of ruminants. ISME J. 2016;10:2958-72. doi:10.1038/ismej.2016.62. 
100. NSW Department of Primary Industries. Genetic technologies to reduce methane emissions from Australian beef cattle. 2015. ISBN 978-1-74256-860-7.

101. Weimer PJ, Stevenson DM, Mantovani HC, Man SLC. Host specificity of the ruminal bacterial community in the dairy cow following near-total exchange of ruminal contents. J Dairy Sci. 2010;93:5902-12.

102. King EE, Smith RP, St Pierre B, Wright ADG. Differences in the rumen methanogen populations of lactating jersey and holstein dairy cows under the same diet regimen. Appl Environ Microbiol. 2011;77:5682-7.

103. Malmuthuge N, Li M, Fries P, Griebel PJ, Guan LL. Regional and age dependent changes in gene expression of Toll-like receptors and key antimicrobial defence molecules throughout the gastrointestinal tract of dairy calves. Vet Immunol Immunopathol. 2012;146:18-26.

104. Liu J, Bian G, Zhu W, Sheng-yong MS. High-grain feeding causes strong shifts in ruminal epithelial bacterial community and expression of Toll-like receptor genes in goats. Front Microbiol. 2015:6:167.

105. Williams YJ, Rea SM, Popovski S, Pimm CL, Williams AJ, Toovey AF, et al. Responses of sheep to a vaccination of entodinial or mixed rumen protozoal antigens to reduce rumen protozoal numbers. Br J Nutr. 2008;99:100-9.

106. Williams YJ, Popovski S, Rea SM, Skillman LC, Toovey AF, Northwood KS, et al. A vaccine against rumen methanogens can alter the composition of archaeal populations. Appl Environ Microbiol. 2009;75:1860-6.

107. Appuhamy JA, Wagner-Riddle C, Casper DP, France J, Kebreab E. Quantifying body water kinetics and fecal and urinary water output from lactating Holstein dairy cows. J Dairy Sci. 2014;97:6177-95.

108. Ross EM, Moate PJ, Marett LC, Cocks BG, Hayes B. Metagenomic predictions: from microbiome to complex health and environmental phenotypes in humans and cattle. PLoS One. 2013;8:e73056.

109. Roehe R, Dewhurst RJ, Duthie CA, Rooke JA, McKain N, Ross DW, et al. Bovine host genetic variation influences rumen microbial methane production with best selection criterion for low methane emitting and efficiently feed converting hosts based on metagenomic gene abundance. PLoS Genet. 2016;12:e1005846.

110. Yu ZT, Morrison M. Improved extraction of PCR-quality community DNA from digesta and fecal samples. Biotechniques. 2004;36:808-12.

111. Edgar RC. MUSCLE: multiple sequence alignment with high accuracy and high throughput. Nucl Acids Res. 2004;32:1792-7.

112. Tamura K, Dudley J, Nei M, Kumar S. MEGA4: molecular evolutionary genetics analysis (MEGA) software version 4.0. Mol Biol Evol. 2007;24:1596-9.

\section{Submit your next manuscript to BioMed Central and we will help you at every step:}

- We accept pre-submission inquiries

- Our selector tool helps you to find the most relevant journal

- We provide round the clock customer support

- Convenient online submission

- Thorough peer review

- Inclusion in PubMed and all major indexing services

- Maximum visibility for your research

Submit your manuscript at wuw biomedcentral.com/submit

C Biomed Central 